AThis is an Accepted Manuscript of an article published by Taylor \& Francis in Aging and Mental Health on 13th October 2020, available online:

https://www.tandfonline.com/doi/full/10.1080/13607863.2020.1830944

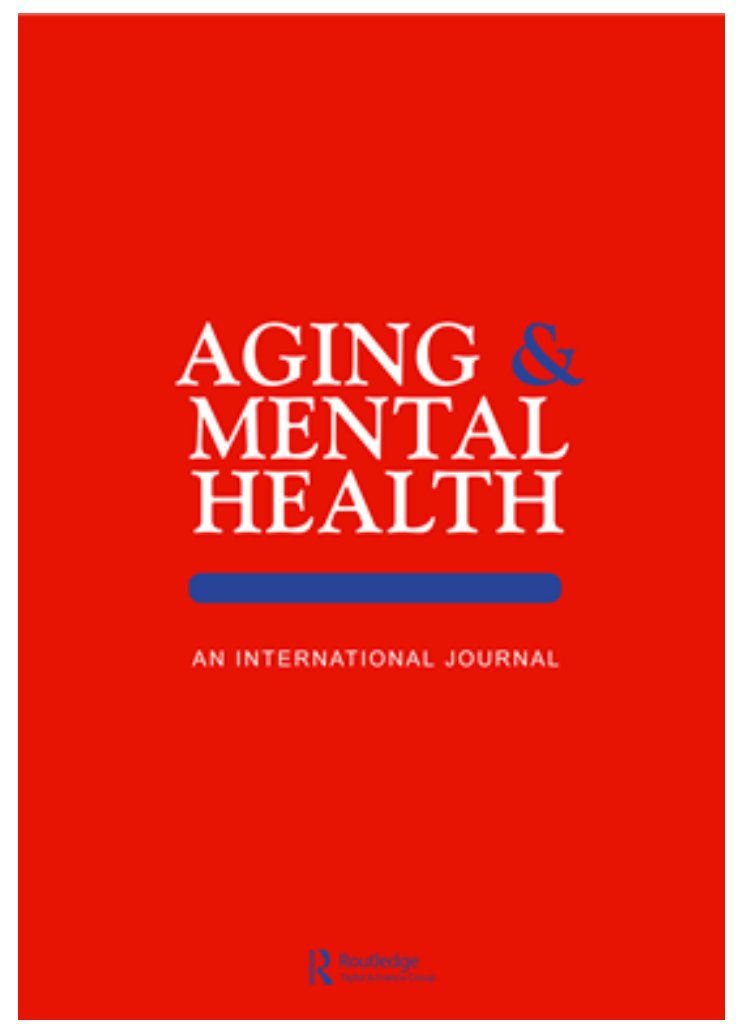

\title{
UK Clinicians' Views on the Use of Formulations for the Management of BPSD: A Multidisciplinary Survey
}

\begin{tabular}{|r|l|}
\hline Journal: & Aging and Mental Health \\
\hline Manuscript ID & CAMH-2020-0540.R1 \\
\hline Manuscript Type: & Research Article \\
\hline Keywords: & Formulation, nonpharmacological, NICE, BPSD, agitation \\
\hline \multicolumn{2}{l}{} \\
\end{tabular}

\section{SCHOLARONE \\ Manuscripts}




\begin{abstract}
Background and Objectives: The process of formulating in the area of dementia care is at an early stage of development. A review published in 2016, identified 14 different types of formulation-based approaches for the management of Behavioural and Psychological Symptoms of Dementia (BPSD). The present study examines professionals' views about the use of systematic formulations for choosing first-line non-pharmacological interventions for BPSD.
\end{abstract}

Methods: A 34-item online survey, with six items about formulation-based interventions for the management of BPSD, was circulated to multi-disciplinary UK dementia networks. Quantitative data were examined for the use of formulation-based frameworks in practice. Thematic analyses provided insight into the practicalities of using formulations.

Results: The majority of the 355 participants responding to the questions stated they used formulation-led models to inform interventions, but $24 \%$ stated they did not. Thirty-two types of formulation frameworks were named, and there was a diverse spread across the UK. The Newcastle model was the most frequently used framework, with fifty percent of the participants who formulated reporting using this framework. Four themes regarding the use of formulation emerged, relating to function, process, reported outcomes and obstacles.

Conclusion: Formulation-based approaches to targeting intervention are becoming popular in dementia care in the UK. More types of formulation frameworks are used in practice compared with the 2016 review. The use of formulations are seen as key to offering an alternative to pharmacological treatments. Understanding both the value of formulation-led approaches and the obstacles to their use are important to implementing NICE 2018 recommendations. 


\section{Introduction}

Current clinical guidance, including the updated NICE Dementia Guidelines (2018) referring to BPSD, recommend using non-pharmacological approaches as first-line interventions before resorting to antipsychotics and benzodiazapines. Exceptions are made when there is a high level of risk requiring sedating or tranquilising, or when an underlying psychotic condition is evident. In general, however, non-drug approaches are supposed to be trialled initially, alongside medications directed at treating any underlying medical conditions that may be sources of agitation (infection, pain, dehydration, thyroid problems, etc.). The British Psychological Society's recent briefing paper recommend the use of formulation-led interventions to aid in the detection and management of BPSD (James and Moniz-Cook, 2018). The Royal College of Psychiatrists (Summers et al. 2017) describe a formulation as an attempt to explain how a situation is developed, maintained or resolved, or is an attempt to make sense of what has happened. The role of formulation has received a lot of attention of late, and many specialist organisations are committed to training all their clinicians in the use of formulation. In the UK the universal use of formulation-led strategies has been successful in many NHS specialisms (adult, child, forensic and learning disabilities), however, problems have arisen in the area of dementia care. In part this is because dementia services cut across many non-mental health organisations (acute NHS care, private sector care homes, home-care providers, day centres, etc.) who are unfamiliar with the term and concept of formulations. Evidence, however, suggests that there is an emergent interest in the use of formulations in this area. For example, Holle et al (2016) identified 14 examples of individualized formulation-led interventions for BPSD. They examined each in terms of structural features and protocols, concluding that the impacts on people with dementia were mixed; half of the frameworks showed significant effects in terms of reductions in BPSD. To understand the current use of formulations in the UK we undertook a survey, examining the views and 
experiences of a diverse multidisciplinary group of clinicians regarding formulation-led approaches for the management of BPSD.

\section{Method}

A multidisciplinary online survey was developed from the views of professionals working in the field of dementia care in the UK. The perspectives were obtained during a one-day consultation workshop organised by the British Psychological Society to review NICE guidelines and examine practice associated with BPSD. This was attended by 74 professionals from a range of professions including psychology (50\%), nursing (14\%), psychiatry (8\%), occupational therapy (OT, 8\%), and other professions e.g. General Practitioner, pharmacy, physiotherapy; care practitioners, social work, family carers, NHS England employees and those employed by dementia charities (between 1 and 3 participants each). Participants were recruited via email from a network of clinical psychologists who worked in services that provided care for people with dementia and from key professional organisations (e.g. Royal Colleges of Psychiatry, GP, Nursing and Occupational Therapy), third sector representation and family carers.

From the consultation event (see James Moniz-Cook and Duffy 2019) a 34-item item questionnaire was developed on the topic of BPSD. The resulting survey was composed of seven sections (Name of concept; Use of management strategies; Knowledge of guidelines; Use of formulations; Training and supervision; Value of specialist teams; Value of existing guidelines). All professionals attending the consultation event, and who consented to be contacted, were sent the online survey. Additional professionals were contacted if they were known by the authors to have a specific interest in the topic; for example from medicine (Geriatricians/ GPs/ Neurology), nursing, speech therapy, social work and experts who had 
published in peer review journals. A cascading snowballing method for recruitment was used.

From the 34-items, six questions related specifically to formulation: Do you use formulations? (Y/N); How often? (likert scale); Who undertakes and who contributes to formulations? (both questions used drop-down choice of professions, plus free text); If you don't use formulations, what approaches/strategies do you use to develop your care plans and interventions? (free text option). Which formulation-led framework is most used for BPSD in your setting? (free text). The latter question was used to identify specific models, which are presented in Table 2.

\section{Data Analysis}

The qualitative data were analysed using the framework analysis method described by Gale et al. (2013). Author MM generated initial codes for 30 of the statements and derived a coding template. IJ then applied the template to the statements. After this process, the framework was amended and applied to a second set of statements in which rating agreement between MM and IJ reached $85 \%$. After this iteration, a final template was developed and MM then coded all of the remaining statements.

\section{Ethics}

The project was approved by the University of Hull Faculty of Health Sciences Ethics committee.

\section{Results}


Responses from 378 participants in total were collected. Over a third (38.6\%) of the overall participants were nurses, with psychologists being the next most frequent contributors (22.2\%), followed by psychiatrists and occupational therapists (see Table 1). Twenty two $(5.8 \%)$ of the 378 participants registering on the survey did not provide any responses on the topic of formulation. Of those providing a response $(\mathrm{N}=356), 273(76.7 \%)$ participants stated they used formulations and $82(23.0 \%)$ reported not using formulation frameworks (Table 1$)$. One hundred and three $(37.5 \%)$ of the total number of participants stating 'yes' to using formulations were nurses, and thus their views are well represented in the survey. In all professional groups, except for GPs, the numbers of participants stating they used formulations were higher than the numbers of participants who did not.

Table 1: Survey of participants and numbers using formulations (column \%)

Table 2 provides details of the formulation models named by the participants in relation to geographical regions. The names of any models mentioned three or less times $(\leq 3)$ in total have not been represented in the table, however, details are presented at the foot of the table. There was good regional representation from across the UK. Table 2 provides the number of participants from each region in the survey, and additionally lists the models used by the 273 participants who stated they used a formulation. Almost a quarter $(24.2 \%, \mathrm{n}=66)$ of those stating they used a model failed to provide a 'named' example. Two hundred and seven respondents outlined a total of 31 'named' frameworks for resolving BPSD (Table 2). The greatest number of participants came from the Yorkshire region, although they were the least likely to use formulations $(60.5 \%)$. Participants from Scotland were the most likely to use a specific formulation, with $95 \%$ of the Scots providing a named approach. 
One hundred and thirty nine (67.1\%) participants stated they used only one model, the remaining third of the participants in this group used several models, ranging from two to four types. This may reflect the need for adaptations across work settings and also that the service-users displaying BPSD are a diverse population. Approximately 50\% (49.8\%) of the respondents stating they used a formulation reported using the Newcastle model (James, 1999, 2011) and 21.6\% employed Kitwood's flower of need (Kitwood, 1997). These were also the only two models used across all regions. Table 2 shows there was regional variation of formulation usage, with particular models being preferred in specific areas. For example, the CLEAR model (Duffy, 2015) is the preferred model in Northern Ireland, where it was developed.

Table 2: Overview of participants' use of the nine most favoured formulation models across the regions of the UK

Of those who indicated they used formulations, $37.5 \%$ used them with 'almost everyone' $(n=104)$ and $30.2 \%$ used them 'often' $(n=83) ; 3.3 \%$ of participants used them rarely $(n=9)$. Twenty-nine respondents did not provide a frequency score (10.5\%). Eighty-four percent rated the use of formulations as either 'extremely useful $(n=131)$ ' or 'very useful' $(n=74)$; $12.3 \%$ stated they were 'moderately useful' $(n=30)$. Less than $3 \%$ rated formulations as either slightly or 'not' useful $(n=7)$. This is from a total of 244 respondents who answered this question on usefulness.

In relation to 'who contributed to the development of the formulations', the formulations were produced with the assistance of a diverse range of professional groups. Of the 242 responses to this question nurses were seen as the greatest contributors to the development of 
Participants worked across different areas, including community, inpatient acute, inpatient mental health, care home settings, and other (Hospices, Memory clinic, GP clinic, Universities, Dementia organisations, retired etc. $n=87$ ). Forty-one percent of staff who answered questions on formulation worked across multiple areas, with 146 (40.9\%) clinicians working across two or more clinical settings. One hundred and ninety-seven $(55.2 \%)$ clinicians worked in community/own home settings as either part or all of their roles; 120 (33.6\%) worked in inpatient mental health as either part or all; $118(33.1 \%)$ worked in care homes as either part or all; $53(15.4 \%)$ worked in inpatient acute as either part or all of their role. In order to obtain insight of which formulations models were used in specific clinical areas, we examined the use of models for those people who worked in only one setting - see Table 3. Table 3 presents the results of the six most frequently used models. The findings show that the Newcastle model is the most frequently used model across all settings, although there is no real difference in acute inpatient settings. Here, 15 of 27 respondents stated they used a formulation while 12 said they did not. The greatest range of models occurred in the community setting.

Table 3: Profile of the six most frequently used models employed by participants who worked exclusively in one specific setting 
A thematic analysis was conducted with the qualitative responses of the participants who stated they used formulation. Four themes emerged from this process: (1) Function, (2) Process, (3) Reported Outcomes, (4) Obstacles.

\section{Function}

Formulations help to address unmet needs and highlight the service users' difficulties (Algase et al. 1996). Additionally, formulations were seen to function as a method to increase knowledge of the person. Numerous responses suggested that formulations increase the awareness of the life of the person with dementia by "allowing everyone in the room to see the person and not just the behaviour." The participants noted that formulations increase feelings of empathy toward the person from care staff as well as family members. Formulation enables "a person centred - rather than problem centred - approach". It was also noted that one of the functions of formulation was to establish personalised interventions that can be used to develop meaningful activities and effective clinical strategies for the person with dementia.

\section{Process}

The process of using formulations was to enable staff to understand the person with dementia better. For example, the following response highlights how 'team' formulations were seen to be beneficial:

\footnotetext{
"Weekly team formulations are used on the wards to help staff understand, get to know and work with individual patients. It enables us all to be working from the same information and allows us to implement interventions in a uniform, consistent way."
} 
Participants suggested that staff valued the collaborative nature of formulating because the process was inclusive and explored perspectives from all individuals - staff and/or family members - working with the person. The joint effort enables people involved in the care to "have a voice" and create a shared plan. Finally, the process of developing a clear, structured, and easily updateable structural framework was seen to be beneficial. The collaborative process meant that the information needed to be understandable to all involved and also written in a clear and concise manner.

\section{Reported Outcomes}

There was a consensus that formulations were helpful and they directly influenced successful outcomes. For example, the following response describes this:

"A detailed, informed formulation leads to more reliable hypotheses regarding unmet needs; and then intervention plans can be tailored in order to meet these needs. This is much more helpful than using a trial and error approach. A well-developed/wellimplemented formulation led intervention plan leads to better outcomes for people with dementia and services."

A less focused 'trial and error' approach was perceived to lead to poorer outcomes because it did not involve an understanding of the person, their life history, and their unmet needs. Many respondents reflected on how using a helpful formulation reduced the need for using psychotropic medication.

\section{Obstacles}

Staff reported practical constraints about formulation, i.e. time constraints, staff shortages, larger caseloads, and extra paperwork associated with the frameworks. One participant said that formulation were not routinely used because the medical model was the principal 
approach on their unit: "Formulation use varies because our service follows a medically dominated model and there's a resistance to working in other ways."

Additionally, it was noted that some services lacked the appropriate training and support to facilitate formulation sessions. On a different, but related problem, it was acknowledged that the degree of helpfulness of a formulation depended on whether the care staff implemented the strategies suggested by the framework; which was not always the case. Thus, participants stated that 'if' staff neither supported nor implemented the formulation-led strategies the use of such frameworks became a 'paper exercise.'

\section{Participants not using formulations}

The 82 participants who stated that they did not formulate were asked to indicate what alternative strategies they used with BPSD. The alternatives are outlined in Table 4. In many situations the 'alternatives' are actually versions of a formulation (see Table 4, section A). The participants appeared reluctant to call them a 'formulation' because of their brevity and/or the lack of comprehensiveness compared to that of established structural frameworks. Nevertheless, the models they employed appear to conform to the description of a formulation given in the introduction.

In section B of Table 4 we see that some participants suggested that either 'care plans' and/or 'clinical meetings' were suitable alternatives to formulations. It would be interesting to determine the process/structure of both the care plans and meetings. For example, if they followed a protocol or a bespoke structure in a formulaic manner, the plans and meetings start to look like a type of formulation. This point is well illustrated in the following quote:

"We do not use formal formulations but in a way we use the approach. We are developing a system of traffic light support plans for each individual resident to 
reflect what they enjoy linked to past and current preferences to include activities, environment, and social interactions and how these may be used to support well-being or reducing distress."

Section C provides examples of practical alternatives to formulation, focusing on the "here and now' interactions rather than background details of people with dementia. It has been argued by Carter (1976) that this approach is how many nurses, in particular, learn their clinical skills. This is a non-strategic approach to nursing care in which staff become skilful through experience and 'doing', and via observation of colleagues.

Table 4: Alternatives to formulations by participants who stated they did not use formulations

\section{Discussion}

The present study used an on-line questionnaire to garner participants' views and perspectives toward formulation. It was shown that more participants used formulations compared to those who reported 'not using' them. The sample had a good representation across region and disciplines. The most frequently used frameworks were the Newcastle model, Kitwood model, and a variety of biopsychosocial conceptualisations. Table 2 provides a good overview of the sample by region and model usage and, while a relatively small number of frameworks dominated, over thirty $(n=31)$ different models were mentioned in the survey. This high number does raise one concern because it may reflect a lack of clarity in the participants' views about the nature of formulations. Indeed, while this survey was specifically aimed at identifying models, it is possible that some of the participants were replying in terms of philosophies rather than specific frameworks. For example, Kitwood's 
work can be viewed in terms of either a person-centred methodology or a conceptualising framework (eg. the flower of needs model). We accept this as a potential weakness, but at the planning stage of the survey we agreed to accept any response within the category of a framework in which both a published framework existed and was known to be being employed clinically. Nevertheless we are mindful of the issue and it is an important potential confound to highlight.

Table 3 presents the results of the six most frequently used models for those participants who only worked in one setting; this analysis gave us a clearer idea of the association between clinical setting and model. The findings showed that the Newcastle model is the most frequently used framework across all settings, although there was no real difference in acute inpatient settings. Here, $52 \%$ of respondents stated they used a formulation, but only $36 \%$ were able to name a specific model. This suggests that in acute settings formulations are not as well established compared to other settings. The greatest range of models occurred in the community setting which could be accounted for by there being a less standardised approach to working with families of various sizes and compositions. This could be contrasted to a ward or care home services, where the organisation or care provider might adopt a specific approach which all the team members would need to adhere to. Thus in the community there may be more scope for individual clinicians to choose which ever model they prefer; hence the greater variety.

Approximately $11 \%$ of staff using formulation frameworks reported not knowing the names of the models they used. Whether participants were unaware of the models they were using or, alternatively, they used generic models, was unclear. Four themes emerged from responses to the open-ended questions: (1) Function, (2) Process, (3) Reported Outcomes, and (4) Obstacles. Formulation was viewed as a useful and helpful method in clinical settings. This was evidenced by three of the four emergent themes reporting positive 
attributes of formulation. For instance, the first theme - Function - included views that formulation benefitted care by increasing knowledge of the person by understanding their life story. Formulation was seen to raise awareness of the person's difficulties through an empathic manner. The Process theme illustrates that staff acknowledge that formulation is an inclusive process that values perspectives from everyone involved across disciplines. The Reported Outcomes theme suggested that use of formulations led to successful interventions, effective care planning, and reductions in the use of psychotropic medications. The above findings are generally consistent with the RCPsych paper entitled 'Using formulation in general psychiatric care: good practice' extoled the virtues and various functions and processes involved in the use of formulations (RCPsych Occasional Paper 103, 2017). Similarly, in a qualitative study undertaken with psychiatrists, Mohtashemi et al (2016) suggested that formulations should be seen as important additions to diagnoses, and used in cases of risk and complexity. They found that psychiatrists valued formulations, particularly when they had support from experienced formulators in the development of the conceptual models. They produced a dynamic diagrammatic model explaining the benefits and obstacles of using formulations. The pros included: achieving a greater understanding of patients' needs, triggers and risks; improved team working; and coproduction. Consistent with the present study, the following cons were mentioned: time restraints; training deficits; and pressure and disagreements.

In considering the perceived Obstacles to formulation, concerns related to practical constraints. For instance, staff shortages and time constraints as difficulties in undertaking formulations. To address this concern the "Mental Health and New Models of Care" document emphasises the importance of upskilling staff to improve their pressured working conditions (Kings Fund, 2017). 
Responses in our survey suggest that knowledge of the formulation process benefits from frequent team formulations sessions or multi-disciplinary team (MDT) case-discussions. Such meetings were reported to enhance knowledge both of the person as well as the formulating process. Despite the quantitative data indicating nurses were undertaking formulations frequently, the notion that formulations are 'largely the domain of psychologists' persists. This is in contrast with the evidence that non-psychologists (i) were involved in developing them, and (ii) were 'formulating' without using this specific term. Indeed, when respondents in the latter group were asked what alternative tools they used in place of formulations, many of their substitutions resembled formulations (Table 4). Examples included obtaining a clinical history, discussing the case with the family, having MDT meetings, assessing communication and interactions skills, using clinical reasoning, etc.

The results in the present survey showed that participants were using formulating methods to explain a person's presentation, though not necessarily using the term 'formulation' or 'formulating' to describe their approaches. This finding is consistent with Reichelt's paper (Reichelt, Moody, Wells \& James, 2019) that argued that many clinical staff harbour the misconception that unless they are using an established conceptual framework (eg. Newcastle model, Kitwood, a Biopsychosocial Model, see Holle et al, 2016), they are not formulating. In order to clarify this issue, let us look at the differing functions of formulations and formulating.

Formulation frameworks provide individualised templates from which to produce care plans and facilitate the actions to be undertaken by staff. The framework is the product of information gathering and assessment, and typically contains information about current behaviour, type of dementia/cognition, history, prior personality and health status (Holle et al. 2016). This information is helpful in producing targeted interventions, but has limitations as a stand-alone model, because it is essentially a summary of data. For these summaries to be 
useful, the component information needs to be integrated and features prioritised, using a problem-solving process. For example, background (distal) features can be linked to 'here and now' behaviours and emotions (proximal) as illustrated in the Newcastle model. The integrated details can be used to produce a hypothesis, care plan and targeted management strategies.

Table 2 provides a list of the names of formulations provided by the participants. It is relevant to note that the formulations are not completely discrete frameworks, with some sharing similar origins. This is well illustrated with the presence of a number of personcentred approaches (VIP and DCM), which have their origins in the work of Kitwood, However, it is relevant to note that Kitwood produced his own specific framework (i.e. The Flower of Need, Kitwood 1997) which many clinicians use as a conceptual model. This level of distinction between person-centred frameworks and philosophy was highlighted in the one-day workshop we described in the method section, and this is why we have not combined all the person-centred models under one category. A similar situation occurred with a number of the models that were based on 'meeting people's needs'. While both CohenMansfield and Maslow (1957) have frameworks based on 'unmet needs', both are distinctive frameworks and therefore were not combined within a single category. Indeed, CohenMansfield's (2000) framework, composed of background and behavioural elements, has been shown in this survey to be one of the most widely used models across UK.

In contrast to the structural formulation frameworks, the process elements are the features concerned with the manner in which the relevant data are collected and used. The process features are not concerned with 'what' information should be collected, but rather 'how best to collect it'. For example, via the use of questioning, education, and collaborating with other team members. For this reason the process features actually drive the awareness, involvement and subsequent understanding of staff, increasing the likelihood they will 
implement the interventions produced from the frameworks. To optimise the benefits of good formulation processes, we have made the following recommendations based on both our discussions from the one-off consultation workshop (linked to the development of the survey), and a programme of work on the use of formulations conducted over a number of years (James, 2011; James and Jackman, 2017).

The formulating process needs to:

- be done over a period of time in order to allow the staff to assimilate, adjust and become stakeholders in the process

- give staff an understanding about why they need to interact or do something differently with the person with dementia

- aim to motivate the staff to do things differently (promote empathy)

- translate into clear behavioural goals (a simple sensible care plan)

- be comprehensive enough to do all the above, but not so complex that it's confusing

If we accept these process features are relevant, we can see why it is important that no one person (or profession) within a clinical service is left solely to produce the framework.

Indeed, if a framework (no matter how comprehensive) suddenly appears within a treatment programme, it is less likely to motivate and inspire changes in people's clinical practices, compared to a framework that has been coproduced. It is relevant to note the limitations of the survey prevented us making any relevant conclusions about the relationship between the use of formulations and non-pharmacological interventions as alternatives to psychotropics for BPSD as recommended in the NICE guidelines. This is an issue that requires future investigation.

Prior to examining the limitations of the study, it is worth noting the influences of some potential organisational biases in relation to model selection. Indeed, the selection of which 
formulations to choose is not always the personal choice of a clinician, but may reflect the management plans of either organisations or regional training programmes. There are at least two examples of such biases in our survey. The first example is seen in the high percentage of use of the CLEAR model in Northern Ireland (Table 2). The usage is explained by the fact that CLEAR was developed locally and has been part of a comprehensive training programme over the last five years in Northern Ireland. Example two is reflected in the high level of use of the Newcastle model in Scotland (Table 2). The Newcastle model was incorporated within NHS Education Scotland's national dementia training programme, owing to it being one of the few models included in an evidence-based training manual (Fossey and James, 2007).

In terms of the limitation of the study, firstly, it is relevant to consider the method of recruitment to the project. The selection involved a prior workshop/meeting and then the targeting of participants who were known to have an interest in the field. While the method enabled us to sample a large population, it probably gave us a more positive perspective on formulation than currently exists in a general population of clinicians. Secondly, $94.2 \%$ of those registering on the survey answered questions on formulations, and so it is not clear why some respondents did not complete this section. Thirdly, the self-report methodology used may have contributed to a response bias. Further since an online questionnaire was used the group was self-selecting and thus the results reflect a people with a particular interest in BPSD. Though there was a heterogeneous sample, with staff from multiple disciplines, a greater number of nurses and psychologists participated in the survey compared to other staff members. This may have skewed the responses provided. As also may have been the case with some regional biases, with high levels of representation from the Yorkshire region. However, a strength of the methodology was its openness for participation from a wide range of disciplines; a large sample of participants were recruited nationally. Another strength was 
the mixed methods approach which generated quantitative and qualitative data, helping to clarify a number of perspectives.

\section{Conclusion}

Amongst our self-selecting participants formulation-use was common, across regions, professions and clinical settings. The results of this survey has provided a good overview of the use of formulations in the UK, and has provided evidence that a large, perhaps increasing, range of formulations are being used. The more established formulations were used more frequently, such as the Newcastle, Kitwood and biopsychosocial models. Although still seen as the domain of psychologists by some, many different professional groups are involved in the development of formulation, which is a positive development.

The qualitative themes showed that formulations were generally seen as beneficial and considered to lead to positive outcomes in BPSD. The potential obstacles related to the system constraints and practical concerns (i.e. staff shortages, lack of resources, time constraints) rather than any negative perspectives of formulation as an actual method. When the 82 participants not using formulations were asked to provide alternatives to the approach, many of these substitutes resembled definitions of formulations (i.e. taking a clinical history, discussing with family, and assessing communication skills). This suggests that clinicians were using problem-solving strategies, similar to formulations 'in all but name' without recognising they were doing so. Staff should be encouraged, and made aware, that they may still be formulating, and have the skills to do so.

\section{References}


Algase, D., Beck, C. Kalanowski, A. et al. (1997). Needs-driven dementia compromised behaviour: an alternative view of disruptive behaviour. American Journal of Alzheimer's Disease, 11(6), 10-19.

Cohen-Mansfield, J. (2000). Use of patient characteristics to determine non-pharmacological interventions for behavioural and psychological symptoms of dementia. International Psychogeriatrics, 12(1), 373-380.

Carper, B. (1978). Fundamental patterns of knowing in nursing. Advances in Nursing Science, 1(1), 13-24.

Duffy, F. (2016). 'Look at all of me' - a CLEAR model for dementia care. Journal of Dementia Care, 24(3), 27-30.

Duffy, F. (2019). CLEAR Dementia Care (C): A Model to Assess and Address Unmet Needs. Jessica Kingsley: London.

Edgar, F. (2017). Mnemonic techniques: how to CEASE stress and distress. Journal of Dementia Care. 25(5), 32-34.

Fossey, J. \& James, I.A. (2007). Evidence-based Approaches for Improving Dementia Care in Care Homes. Alzheimer Society. Gordon House: London.

Gale, N.K., Heath, G., Cameron, E., et al. (2013). Using the framework method for the analysis of qualitative data in multi-disciplinary health research. BMC Medical Research Methodology 13, 117. https://doi.org/10.1186/1471-2288-13-117

Holle, D., Halek, M., Holle B. \& Pinkert, C. (2016). Individualized formulation-led interventions for analyzing and managing challenging behavior of people with dementia: An integrative review. Aging and Mental Health, 21 (12), 1247-1249. DOI: $10.1080 / 13607863.2016 .1247429$. 
Kales, H. Gitlin, L and Lyketsos, C. (2015). Assessment and management of behavioral and psychological symptoms of dementia. British Medical Journal. 350: h369. doi: 10.1136/bmj.h369. Published online 2015 Mar 2

Kales H., Gitlin, L. and Lyketsos C.G. (2019). The Dice Approach: Guiding the Caregiver in Managing the Behavioral Symptoms of Dementia. Michigan University Press: Michigan.

James, I.A. (1999). Cognitive conceptualisation of distress in dementia. Clinical Psychology Forum. 133, 21-25.

James, I.A. (2011). Understanding Behaviour in Dementia that Challenges: A guide to assessment and treatment. Jessica Kingsley: London.

James, I. and Moniz-Cook, E. (2018). Behaviour that Challenges in Dementia. BPS Advisory Group. https://www.bps.org.uk/sites/bps.org.uk/files/Policy/Policy

James, I. \& Moniz-Cook, E. (2018). Behaviours that Challenge in Dementia. A Briefing Paper for the British Psychological Society. BPS, Leicester.

Kings Fund (2017). Mental health and new models of care: lessons from the vanguards. https://www.kingsfund.org.uk/publications/mental-health-new-care-models

Kitwood, T. (1997). Dementia Reconsidered. Open University Press.

Maslow, A. (1954). Motivation and Personality. New York: Harper and Row.

Mohtashemi, R., Stevens, J., Jackson, P.G., \& Weatherhead, S. (2016). Psychiatrists' understanding and use of psychological formulation: a qualitative exploration. BJPsych Bulletin. 40(4):212-216. doi: 10.1192/pb.bp.115.051342. 
NICE (2018). Dementia: assessment, management and support for people living with dementia and their carers. https://www.nice.org.uk/guidance/ng97

Royal College of Psychiatrists (2017). Using Formulation in General Psychiatric Care: Good Practice. Occasional Paper 103. Royal College of Psychiatrists.

Reichelt, K., Moody, L. Wells, J. \& James I.A. (2019). Formulating and formulations in dementia care: Reviewing our perspectives. Psychology of Older People: The FPOP Bulletin, 148, 17-25.

Summers, A., Boland, B., Dave, S., Gill, H., Ingrams, C., \& Saju, P. (2017). Using formulation in general psychiatric care: good practice. Royal College of Psychiatrists. 
Table 1: Survey of participants and numbers using/not using formulations (column \%)

\begin{tabular}{|l|c|c|c|}
\hline Occupation & $\begin{array}{l}\text { Respondent } \\
\text { registered in } \\
\text { survey }\end{array}$ & $\begin{array}{c}\text { Said 'Yes' to } \\
\text { using } \\
\text { formulations }\end{array}$ & $\begin{array}{c}\text { Said 'No' to } \\
\text { using } \\
\text { formulations }\end{array}$ \\
\hline $\begin{array}{l}\text { Total Nurses (including } \\
\text { Admiral nurses) }\end{array}$ & $\begin{array}{c}146(38.6 \% \text { of } \\
\text { survey respondents } \\
\text { were nurses) }\end{array}$ & $\begin{array}{c}103(37.5 \% \text { of } \\
\text { participants saying } \\
\text { 'yes' were nurses) }\end{array}$ & $\begin{array}{c}30(36.6 \% \text { of } \\
\text { participants saying } \\
\text { 'no' were nurses }\end{array}$ \\
\hline Clinical Psychologists & $84(22.2 \%)$ & $80(29.1 \%)$ & $2(2.4 \%)$ \\
\hline Psychiatrists & $38(10.1 \%)$ & $30(10.9 \%)$ & $6(7.3 \%)$ \\
\hline Occupational Therapists & $25(6.6 \%)$ & $20(7.3 \%)$ & $5(6.1 \%)$ \\
\hline General Practitioners & $7(<1 \%)$ & $2(<1 \%)$ & $5(6.1 \%)$ \\
\hline Social Workers & $6(<1 \%)$ & 0 & $1(1.2 \%)$ \\
\hline Care staff & $3(<1 \%)$ & $2(<1 \%)$ & $1(1.2 \%)$ \\
\hline $\begin{array}{l}\text { Others (assistant } \\
\text { psychologists, pharmacists, } \\
\text { physiotherapists, } \\
\text { researchers, third sector, } \\
\text { neurologist, home care } \\
\text { workers) }\end{array}$ & $69(18.3 \%)$ & $36(13.8 \%)$ & $32(39.0 \%)$ \\
\hline \begin{tabular}{l} 
TOTALS \\
\hline
\end{tabular} & 378 & 273 & 82 \\
\hline
\end{tabular}


Table 3: Profile of the six most frequently used models employed by participants who worked exclusively in one specific setting

\begin{tabular}{|l|c|c|c|c|c|}
\hline $\begin{array}{l}\text { Top 6 formulat- } \\
\text { ion models }\end{array}$ & $\begin{array}{c}\text { Community/ } \\
\text { Own home }\end{array}$ & $\begin{array}{c}\text { Mental h'lth } \\
\text { inpatient }\end{array}$ & $\begin{array}{c}\text { Acute } \\
\text { inpatient }\end{array}$ & Care home & Other \\
\hline Newcastle & 19 & 23 & 3 & 9 & 22 \\
\hline $\begin{array}{l}\text { Cohen } \\
\text { Mansfield }\end{array}$ & 3 & 2 & 2 & 2 & 4 \\
\hline $\begin{array}{l}\text { Functional } \\
\text { analysis }\end{array}$ & 1 & 1 & 2 & 1 & 1 \\
\hline CLEAR & 0 & 4 & 1 & 3 & 2 \\
\hline $\begin{array}{l}\text { Kitwood flower } \\
\text { need }\end{array}$ & 14 & 4 & 0 & 0 & 11 \\
\hline Biopsychosocial & 9 & 4 & 1 & 1 & 1 \\
\hline $\begin{array}{l}\text { Said 'No' to using } \\
\text { formulations }\end{array}$ & 22 & 4 & 12 & 2 & 20 \\
\hline $\begin{array}{l}\text { Said 'Yes' to using } \\
\text { formulations }\end{array}$ & 54 & 43 & 13 & 13 & 38 \\
\hline $\begin{array}{l}\text { 'Yes', but not state } \\
\text { name of formul'n* }\end{array}$ & 8 & 6 & 4 & 0 & 0 \\
\hline
\end{tabular}

*The figures do not add up exactly due to some participants stating they used formulation and then failing to state the name of a formulation, and some people using a number of different formulations. 
Table 4: Alternatives to formulations by participants who stated they did not use formulations

A. Alternative Conceptual Models (Proxy formulations)

- "Clinical history. Discussion with family. Understanding the past. Review of behavioural chart. Discussion with staff." (Psychiatrist)

- "Take a thorough personal history and social history; review previous contact with mental health services; physical health history, recent tests and examinations, medications current and past, issues which could be contributing e.g. pain; description of the problem/s e.g. duration, frequency, severity, symptoms, triggers; review any notes e.g. daily care records, $\mathrm{ABC}$ charts; liaise with relatives and carers for their perspective; cognitive testing if appropriate; observation periods.” (Nurse)

- "I take a history and examine, get a collateral history. In general practice we only have 10 mins - so I don't have time to do a proper psychiatric formulation. However, I do use all the data to inform a differential list of why a PwD may be behaving that way - are they in pain etc., have they not had their regular pain relief, is there an infection, etc." (General Practitioner, GP).

\section{B. Care Plans and Meetings as Alternatives}

- "Care planning, formal assessment, MDT meetings." (GP)

- "Multi-disciplinary assessments and care planning." (Nurse)

- "Through initial and ongoing assessment where knowledge is gained about the person that is then used to create care plans that reflect personal history, preferences, likes and dislikes." (Occupational therapist, OT)

- "Psych team input." (Nurse)

- "Multi-disciplinary team assessment - OT and nursing." (OT) 


\section{Communication and Interaction Skills}

- "Assess the person with dementia's communication skills and interactions and how these impact on behaviour, assess the communication of the people around the person with dementia and how this impacts, provide education and advice and strategies to those around the person, one to one input if able.” (Speech \& Language Therapist)

- $\quad$ "I look and learn from the people I work with and alter my behaviour and interactions accordingly.” (Member of Alzheimer Society)

\section{Other Miscellaneous Responses}

- "We ask the individual and the people who know them best." (GP)

- $\quad$ "History and examination. May use ABC. Time pressured services and clinical assessment pre-empts use of lengthy assessment tools.” (Psychiatrist)

- "Trial and error." (Dementia Researcher)

- "Often it is hit and miss; sometimes an attempt is made at attempting a patient's life story and speaking to family to try and understand certain behaviours." (Nurse)

- “Clinical reasoning." (OT)

- “Empirical.” (Psychiatrist)

- "Based in Accident \& Emergency so information collected largely dependent on time of day and staff involved, currently working to improve care that this group of vulnerable patients receive." (Nurse)

- "I am aware of formulations, but do not use this as I'm a researcher." (Researcher) 


\begin{tabular}{|c|c|c|c|c|c|c|c|c|c|c|}
\hline \multirow{3}{*}{$\begin{array}{l}\text { Number saying } \\
\text { 'Yes' to using a } \\
\text { formulation by } \\
\text { region / } \\
\text { Total participants } \\
\text { from region }(\%) * \\
\end{array}$} & & & & & & & & & & \\
\hline & \multicolumn{9}{|c|}{ Responses to: Which formulation-led framework is most used for BPSD in your setting? } & \multirow{2}{*}{$\begin{array}{l}\text { Stated } \\
\text { 'YES', but } \\
\text { not state } \\
\text { name of } \\
\text { model }\end{array}$} \\
\hline & Newcastle & Kitwood & $\begin{array}{l}\text { Biopsycho } \\
\text { social }\end{array}$ & $\begin{array}{l}\text { Cohen- } \\
\text { Mansfield }\end{array}$ & CLEAR & $\begin{array}{l}\text { Functional } \\
\text { Analysis }\end{array}$ & Stokes & $\begin{array}{l}\text { Person- } \\
\text { centred }\end{array}$ & CEASE & \\
\hline $\begin{array}{l}\text { Yorkshire } \\
\mathrm{N}=52 / 86(60.5 \%)^{*}\end{array}$ & 16 & 5 & 7 & 5 & 0 & 4 & 4 & 0 & 0 & 22 \\
\hline $\begin{array}{l}\text { Midlands } \\
\mathrm{N}=30 / 47(63.8 \%)^{*}\end{array}$ & 12 & 12 & 5 & 1 & 0 & 1 & 2 & 2 & 0 & 9 \\
\hline $\begin{array}{l}\text { Scotland } \\
\mathrm{N}=38 / 40(95.0 \%) *\end{array}$ & 37 & 8 & 4 & 5 & 0 & 6 & 0 & 1 & 0 & 0 \\
\hline $\begin{array}{l}\text { N. East England } \\
\mathrm{N}=29 / 37(78.4 \%)^{*}\end{array}$ & 19 & 6 & 2 & 1 & 0 & 2 & 1 & 0 & 4 & 4 \\
\hline $\begin{array}{l}\text { South England \& } \\
\text { Chan. Isles } \\
\mathrm{N}=26 / \mathbf{3 8}(68.4 \%)^{*}\end{array}$ & 15 & 12 & 3 & 3 & 1 & 2 & 0 & 0 & 0 & 4 \\
\hline $\begin{array}{l}\text { NW England. } \\
\mathrm{N}=25 / 33(75.8 \%)^{*}\end{array}$ & 12 & 7 & 1 & 0 & 0 & 1 & 0 & 2 & 0 & 6 \\
\hline $\begin{array}{l}\text { London area } \\
\mathrm{N}=27 / 32(84.4 \%) *\end{array}$ & 9 & 2 & 4 & 2 & 1 & 1 & 0 & 0 & 0 & 12 \\
\hline $\begin{array}{l}\text { Northern Ireland } \\
\mathrm{N}=23 / 27(85.2 \%) *\end{array}$ & 2 & 2 & 0 & 2 & 17 & 0 & 0 & 0 & 0 & 4 \\
\hline $\begin{array}{l}\text { Wales } \\
\mathrm{N}=14 / \mathbf{2 1}(66.7 \%)^{*}\end{array}$ & 8 & 2 & 2 & 1 & 1 & 1 & 0 & 0 & 0 & 4 \\
\hline $\begin{array}{l}\text { Cumbria \& Lancs } \\
\mathrm{N}=9 / 12(75.0 \%)^{*}\end{array}$ & 6 & 3 & 0 & 0 & 0 & 0 & 0 & 1 & 0 & 1 \\
\hline & 136 & 59 & 28 & 20 & 20 & 18 & 7 & 6 & 4 & $66 * *$ \\
\hline
\end{tabular}




\begin{tabular}{|c|l|l|l|l|l|l|l|l|}
\hline TOTALS*** & & & & & & & & \\
$273 / 373(73.2 \%)$ & & & & & & & & \\
\hline
\end{tabular}

*Percentage of participants from a region who stated that they used a formulation.

** $66(24.1 \%)$ of those stating they used a formulation 'did not/were unable' to specify a 'named' model.

*** Four participants did not state the region in which they worked.

\section{Other models mentioned:}

Dementia Care Mapping; Teepa Snow/PCA; Positive Behavioural Support (N=3 respondents used this model)

Tees Esk \& Wear model; Systemic; DICE; Brooker/VIP (N=2)

Cognitive Behaviour Therapy; Maslow; Mixed model; Attachment theory; Psychodynamic; Education; Applied behaviour analysis; Relationship-centred model ( $\mathrm{N}=1)$

Table 2 